\title{
Nasogastric Intubation
}

National Cancer Institute

\section{Source}

National Cancer Institute. Nasogastric Intubation. NCI Thesaurus. Code C91836.

A procedure involving the insertion of a plastic tube into the stomach through the nose. 